\title{
The Informational Role of Voluntary Certification: Evidence from the Mexican Clean Industry Program
}

\author{
By ANDREW D. FOSTER AND EMILIO GUTTIEREZ*
}

* Foster: Brown University, 64 Waterman St, Providence, RI 02912; Guttierez, Centro de Investigacion Economica, ITAM. Camino a Sta. Teresa \#930, Heroes de Padierna, Mexico, DF, CP 10700. Acknowledgement: This work was partially funded by FUDEF grant and by the Population Studies and Training Center at Brown University. The PSTC receives core support from Eunice Kennedy Shriver National Institute of Child Health and Human Development (5R24HD041020). Ricardo Gonzalez-Chagin provided excellent research assistance.

While it has long been recognized that voluntary certification programs designed to reduce emissions can importantly complement command and control regulation (e.g., Ayres and Braithwaite 1992), an absence of empirically validated regulatory models has hampered the design and implementation of such programs. Instead, much of the policy debate has focused on certification programs as an alternative to other forms of environmental controls and on whether voluntary programs result in reduced environmental impact among participatory firms. Particular skepticism has been directed toward the use of voluntary programs in developing countries due to low levels of regulatory capacity, pressure on the part of firms to compete in a global economy, and low levels of household income (Blackman, 2009; Anton, Deltas and Khanna, 2004).
In this paper we argue that voluntary certification can play an important role in the revelation of information about firm costs of compliance that can, in turn, increase the efficacy of command and control regulation. In particular, we suggest that in the presence of perfectly observable environmental behavior, there would be little point to a program that provides some kind of public acknowledgement in the form of a “certificate”. But given imperfect information, certification programs give firms a structured opportunity to signal information about their underlying cost structure. The consequent revelation of information can be of value to both regulators and to other economic agents such as financiers. In particular, if the process of certification reveals information about plants that certify, it also reveals information about those that do not. This information may be used in turn to more efficiently target inspections and thus to alter the behavior of uncertified plants. At the same time, if certification signals to financiers that a firm is in compliance and thus not subject to the risk of a failed inspection, then some firms will benefit from this signaling, thus providing an 
appropriate incentive for compliant firms to engage in certification in the first place. In a sense the problem of selection that has plagued much of the previous empirical literature on voluntary certification is the primary potential source of benefit of such programs.

To clarify this point we first summarize the results from Foster and Gutierrez (2012). That paper introduces a simple theoretical model that captures the interaction of firm and regulator behavior in the presence and absence of voluntary certification and then uses that model to structure an analysis of Mexico's "Clean Industry Program". Results suggest that plants participating in the program are those with the lowest compliance cost within sectors and that regulators use the information revealed by certification to redesign their inspection strategy, increasing the incentives of non-certified firms incentives to improve their environmental performance. We then consider a further implication of the model: that if certification plays an informational role and low costs firms are most likely to certify, then the announcement of certification should have a positive effect on firm valuation. In particular we use data from four multi-plant publicly traded firms to conduct an event study of certification announcements. Consistent with the model, we find evidence of positive price shocks on the day of the announcement.

\section{Environmental Regulation in Mexico}

The primary responsibility for environmental control in Mexico lies with the Mexican Federal Environmental Protection Agency (Procuraduría Federal de Protección al Ambiente, PROFEPA). The agency is responsible for inspecting plants in order to determine if they comply with the current legal pollution emission standards. Inspections are performed at random, assigning a higher probability of inspection to sectors with higher perceived risk of polluting and to larger firms. If a plant is found to be out of compliance, a substantial fine is imposed.

In addition, in 1994 PROFEPA introduced the Mexican Clean Industry Program (Programa de Industria Limpia), which is also known as the National Environmental Auditing Program (Programa Nacional de Auditoría Ambiental). Plants participating in the Clean Industry Program have to pay for an audit by an independent agency on a list maintained by PROFEPA. Auditors evaluate emissions as well as the physical plant and determine the actions that need to be taken in order to make the plant compliant with the pollution emissions standards. Formally, the requirements for certification are only that the plant meets existing standards. However, 
because auditors monitor plant capital, there is some differences in the consequences for the firm of certification relative to compliance without certification. In any case, after it has been established that the plant meets the pollution standards, it is granted a Clean Industry Certificate, which can be used for marketing purposes and to demonstrate to financial institutions, for example, that it is not subject to a potential adverse shock arising from a failed emissions inspection. If certified, plants are then exempted from inspections for a specified period of time (at least two years).

\section{Selection, Revealed Information and the Regulator's Response}

Foster and Gutierrez (2012) develop a model of environmental regulation that integrates plant and regulator behavior and incorporates a combination of voluntary and mandatory controls, based on and applied to Mexico’s Clean Industry Program. The model assumes that plants have a choice between three different options: complying with pollution emissions standards without getting certified; compliance with emissions standards and obtaining a "Clean Industry Certificate"; and non-compliance. All certified plants are assumed to be in compliance, but not all the non-certified plants are non-compliant. Each of the options has a different cost for each plant, depending both on the types of goods they produce (industrial sector) and plant specific characteristics. Each plant chooses the option that has the lowest cost for it given the regulator-determined probability of inspection. Regulators choose the probability of inspection to maximize compliance net of the cost of inspections based on the sectorlevel compliance cost.

In particular, the cost of compliance with pollution emissions standards without certification for plant $i$ in sector $j$ is:

(1) $C_{i j}^{c 1}=C_{j}+d_{i j}$

where $C_{j}$ is the sector $j$ level cost and $d_{i j}$ is the plant specific cost with a distribution $F(d)$, which we assume to be differentiable and concave and invariant by sector. Net costs of compliance for those plants that certify may differ from costs associated with compliance without certification for a variety of reasons including (a) possible marketing benefits (b) reductions in liability and thus improved credit terms (c) the costs of an audit (d) the grace period provided and (e) a need to upgrade capital in order to meet the terms of an audit. These costs may affect differentially the observable and unobservable components of compliance costs so we assume that the cost of certification (net of the benefits) can be approximated by a linear function of these cost components: 
(2) $C_{i j}^{c 2}=\mu+\alpha C_{j}+\beta d_{i j}$

where $\alpha, \beta$, and $\mu$ are constants that are common to all plants. Finally, the cost of noncompliance is given by:

$$
C_{i j}^{n c}=P_{j} \times M
$$

where $P_{j}$ is the probability that the authorities will inspect a plant in sector $j$ and $M$ is the fine imposed if the inspected plant is found to be out of compliance. $M$ is assumed to be fixed and exogenous and $P_{j}$ is set at the sector level, given that regulators are unable to observe (or are precluded, for reasons of transparency, from using) the plants' specific $d_{i j}$.

Given this setup, in the absence of certificates, it is clear from equation (1) and (3) that only plants with low $d_{i j}$ will comply with pollution emissions standards. However, in the presence of certification the values of $\mu$, $\alpha$ and $\beta$ will determine who chooses to get certified. While theoretically we do not impose restrictions on the values of these parameters, we restrict attention to cases in which there is an interior solution in each sector, given that for each sector in our data plants are observed in each of the three regimes.

The regulator is assumed to receive a benefit $A$ for every compliant plant and to pay a cost of $B$ for every inspection. As it knows both the base-line cost of compliance at the sector level, $C_{j}$ and the distribution of $d_{i j}$, the regulator maximizes benefits minus costs through the choice of inspection probabilities by sector. Denoting by $N_{j}$ the number of firms in sector $\mathrm{j}$ and by $L_{j}$ and $D_{j}$, respectively, the endogenously determined fraction of plants in compliance (inclusive of those certified) and those certified in sector $j$, we can then formally write the regulator's problem as the problem of maximizing the following function with respect to $P_{j}$.

(4) $S(\vec{P})=A \sum_{j} N_{j} L_{j}-B \sum_{j} N_{j} P_{j}\left(1-D_{j}\right)$

This model generates for different regimes of $\alpha, \beta$ and $\mu$ a series of distinct implications for patterns of pre- and post-certification sector-specific rates of inspection, failed inspection and certification across sectors. These implications are tested using a combination of information on certification, inspection, and inspection failure. The fact that the inspection probability multiplies only the non-certified population plays a critical role in the analysis: the higher the level certification in a particular sector the lower the cost of a given marginal increase in inspection probability in that sector.

Table 1 presents the three basic relationships observed in the sector-level data. Column 1 shows the output of a regression 
using as a dependent variable the log of one plus the fraction of non-compliant plants before the introduction of certificates, on the $\log$ of one plus the fraction of plants inspected in each sector before the introduction of the certification program (instrumented with inspection probabilities in the US), the fraction of the production that is exported by each sector, the number of employees per plant, and 2-digit sector fixed effects; Column 2 uses the log of one plus the fraction of firms certified in each sector as the dependent variable and the same set of controls; Column 3 presents the same specification with the log of one plus the fraction in non-compliance after the introduction of the certification program as the dependent variable. The three basic relationships observed in the data are then that: pre and post certification are uncorrelated with inspections pre-certificates, and certification is positively correlated with pre-certification inspection rates.

Given these relationships, we can identify the selection regime. In particular, we find that $\beta<1$ and $\mu<(1-\alpha) C_{j}$ so that certified plants have the lowest cost of compliance within sector and compliant firms have intermediate costs of compliance within sector). Surprisingly, we can also derive the shape of the distribution of $d_{i j}, F()$.
Using this information we can draw further implications from the model. In particular, inspection probabilities should increase differentially in sectors with high previous inspection. Table 1, Column 4 shows the results of the same specification as the previous three columns, using the change in inspection probabilities around the introduction of the certification program as the dependent variable. As predicted, the introduction of certification leads to greater increases in inspection probabilities in high cost relative to low cost sectors. Because noncertified firms respond to higher rates of inspection, certification thus leads not only to higher compliance overall but particularly in high cost sectors.

By implication, voluntary certification can have an impact on the overall compliance of a sector even if it has no effect at all on the compliance of firms that choose to certify. From this perspective, whether or not certified firms are likely to adopt more green behavior, the focus of almost all of the prior empirical literature on the subject, is beside the point. The primary benefit of a certification program may lie instead in its ability to reveal information about firms that then permits more efficient targeting of regulator effort. This result may also explain why a government sponsorship of the program is 
important: non-governmental voluntary organizations such as those used by ISO 14001 (see, e.g., Potoski and Prakesh 2005) will not generally internalize the benefits to the regulators or certification.

[ Insert Table 1]

\section{Certification, Information and Capital Markets’ Response}

Having observed circumstantial evidence of the informational benefits of certification, it is useful to look directly for evidence that the program reveals information to other agents. Understanding the potential gains from certification may also help to illuminate the potential value of financial institutions in the context of low regulatory capacity to incentive local firms to comply with formal regulations.

In particular, while it is generally argued that firms in low and middle-income countries have little incentives to comply with environmental standards, Dasgupta et al (2001) find evidence, for the context of Chile, Mexico and the Philippines from 1990 to 1994, that capital markets do respond to the announcement (in the news) of firms' pollution control efforts. As a Clean Industry Certificate explicitly removes a firm from the risk of failing an environmental audit, it should be seen as a positive information shock on the part of financial markets unless markets already have full information on the extent of compliance of the firm. More generally, we would expect a positive reactions of capital markets to certification if certification reveals favorable information about a firm's characteristics such as that it has relatively low cost of compliance or that it is likely to be more successful in marketing to green consumers.

In order to test if the granting of certificates is rewarded by capital markets, we thus perform a simple event study. In particular, we identify four Mexican multi-plant publicly traded firms to which we were able to assign the specific dates at which a Clean Industry Certificate was granted over the 2003-2007 period. Table 2 presents the names of the publicly traded firms and the specific dates at which these events occurred.

\section{[ Insert Table 2]}

We then calculated the daily return of that firm's stock price in the Mexican stock market during the ten days before and after the date at which each certificate was granted, and ran the following regression, at the event level:

$$
\gamma R I P C_{t}+\sum_{w=1}^{5} \gamma_{w} D_{w i t}+\varepsilon_{i t}
$$

where $R_{i t}$ measures the return on the stock of the firm receiving certificate $i$ on period $t$; the 
$\alpha_{i}$ s indicate event fixed effects; $\tau_{i}$ indicates the period at which the certificate $i$ was granted; $R I P C_{t}$ indicates the daily return of the Mexican stock market in period $t$; $D_{\text {wit }}$ are day of the week dummies; and $\varepsilon_{i t}$ is an error term. Our coefficients of interest in this regression are the $\beta_{d}$, which will measure if the return to the stock was on average significantly different during the seven days around the event date (three days before and three days after) from the returns observed in the tenth to fourth periods before and fourth to tenth periods after the event date. If capital markets responded positively to the granting of the Clean Industry Certificate, we expect $\beta_{0}$ to be positive and significantly different from zero. Also, if the abnormal return on the stock coincides with the date at which the certificate was granted, we expect $\beta_{-3,} \beta_{-2}$ and $\beta_{-1}$ to not differ significantly from zero.

Regression results are presented in Table 3. Column one presents the results when only including firm-event fixed effects, day of the week dummies, the stock market daily return rate and the dummy indicating the event date as explanatory variables. Columns 2 and 3 additionally include dummies for one and two days before and after the event as controls, respectively. The coefficient associated with the event-period dummy is consistently positive and significantly different from zero, suggesting that the stock return was one percent higher than average at the dates when certificates were granted. Moreover, when including the dummies for the periods before and after the event date, none of those coefficients is significantly different from zero. The results suggest that capital markets respond positively to the granting of a Clean Industry Certificate to a firm's plant, as the return on that firm's stock is, on average, approximately one percent higher.

The granting of these certificates seems then to reveal information to capital markets about firms' level or cost of compliance which is otherwise not known. Unfortunately the methodology does not permit us to distinguish between a rise in stock prices that is attributable to the fact that certified firms are no longer at risk of failing an environmental audit and thus paying the resulting fine or to other benefits such as an increased market sizes if consumers are known to respond to Certification. Either way, however, this result suggests that capital markets and regulatory agencies, in a context of limited information and weak enforcement, can interact in order to increase firm's compliance with formal regulations.

\section{[ Insert Table 3]}




\section{Conclusions}

Recent high profile accidents and labor unrest associated with the global supply change have brought renewed focus to the promise and pitfalls of voluntary regulation in developing countries. This paper, while focusing an environmental voluntary certification program in Mexico has implications for this debate. In particular, the results suggest that mandatory standards and voluntary programs are not substitutes but are in fact complementary. A well designed certification program can increase the efficacy of a program of government inspections and a program of inspections, in turn, can increase the efficacy of a voluntary program. Moreover since non-governmental organizations will not fully internalize the benefits of voluntary certification, government intervention in the design and implementation of these programs is warranted.

\section{REFERENCES}

Ayres, Ian and John Braithwaite. 1992. Responsive Regulation: Transcending the Deregulation Debate. Oxford, Uk: Oxford University Press.

Anton, Wilma, George Deltas and Madhu. Khanna. 2004. "Incentives For Environmental Self-Regulation and
Implications for Environmental Performance”, Journal of Environmental Economics and Management, 48: 632-654. Blackman, Allen. 2009. Can Voluntary Environmental Regulation Work in Developing Countries? Lessons from Case Studies. Policy Studies Journal 36(1): 11941.

Dasgupta, Susmita, Benoit Laplante And Nlandy Mamingi. 2001. "Pollution And Capital Markets In Developing Countries”. Journal of Environmental Economics and Management 42(3): 310-335.

Foster, Andrew and Emilio Gutierrez. 2012.

"Direct and Indirect Effects of Voluntary Certification: Evidence from The Mexican Clean Industry Program”. Mimeo.

Potoski, Matthew and Aseem Prakesh. 2005. "Green Clubs and Voluntary Governance: ISO 14001 and Firms' Regulatory Compliance", American Journal of Political Science, 49(2):235-48. 


\section{Table 1}

Regression Results. Relationship Between Inspections Pre-Certification, Non-Compliance and the Change in Inspection Probabilities.

\begin{tabular}{lcccc} 
Dependent variable & $\begin{array}{c}\text { Non- } \\
\text { Compliance Pre- } \\
\text { Certificates }\end{array}$ & Certification & $\begin{array}{c}\text { Non- } \\
\text { Compliance } \\
\text { Post- } \\
\text { Certificates }\end{array}$ & $\begin{array}{c}\text { Change in } \\
\text { Inspections }\end{array}$ \\
\hline $\begin{array}{c}\text { Log Fraction Inspected } \\
(92-95)\end{array}$ & -0.0057 & 0.9462 & 0.0489 & 0.3893 \\
Percentage of production & {$[0.0199]$} & {$[0.1964]^{* * *}$} & {$[0.0349]$} & {$[0.2269]^{*}$} \\
exported & 0.0001 & -0.0013 & -0.0003 & -0.0014 \\
Employees per firm & {$[0.0001]$} & {$[0.0012]$} & {$[0.0002]$} & {$[0.0014]$} \\
Sector FixedEffects & -0.00007 & 0.0021 & -0.0002 & 0.0004 \\
Constant & {$[0.0001]$} & {$[0.0012]^{*}$} & {$[0.0002]$} & {$[0.0014]$} \\
& Yes & Yes & Yes & Yes \\
Observations & -0.2008 & 3.4909 & -0.2402 & 0.6359 \\
\hline
\end{tabular}

Standard errors in brackets

* significant at $10 \%$; ** significant at $5 \%$; *** significant at $1 \%$

The log of one plus the fraction inspected in 1992-1995 is instrumented with the log of one plus the fraction inspected in the United States in each sector. Non-Compliance Pre-Certificates is defined as the log of one plus the fraction of failed inspections in each sector between 1992 and 1995. Non-Compliance Post-Certificates is defined as the log of one plus the fraction of failed inspections in each sector between 2003 and 2006. Certification is defined as the log of one plus the ratio of total certificates granted and the number of plants in each sector. The change in inspection is defined as the difference in the fraction inspected in 2006-2003 and the fraction inspected in 1992-1995 in each sector. For a detailed description of all data sources, see Foster and Gutierrez (2012). 


\begin{tabular}{cc}
\hline Firm & $\begin{array}{c}\text { Dates of Certification } \\
\text { (MM/DD/YYYY) }\end{array}$ \\
ALFA, SAB de CV (ALFA) & $4 / 28 / 2004,5 / 20 / 2004,6 / 23 / 2003$, \\
& $8 / 7 / 2003,3 / 9 / 2007$ \\
GRUPO BIMBO, SAB de CV & $2 / 23 / 2007,3 / 14 / 2007,3 / 29 / 2007$, \\
(BIMBO) & $5 / 25 / 2007,6 / 22 / 2007,7 / 6 / 2007$, \\
& $8 / 29 / 2007,9 / 12 / 2007,11 / 9 / 2007$, \\
de CV (PASA) & $2 / 25 / 2004$ \\
PROMOTORA AMBIENTAL, SAB & $24 / 01 / 2006,19 / 12 / 2006,25 / 04 / 2007$, \\
$20 / 08 / 2007$ \\
VITRO, SAB de CV (VITRO) & $21 / 01 / 2003,09 / 12 / 2003,29 / 04 / 2004$, \\
& $20 / 09 / 2004,13 / 01 / 2005,03 / 05 / 2006$ \\
\hline
\end{tabular}

Table 3

Regression Results

Daily Stock Returns around Certification Date

Dependent Variable: Daily Stock Return

Two days before the event

$-0.003$

[0.003]

One day before the event

$-0.006 \quad-0.006$

Event day

0.008 [0.005] [0.005]

One day after the event $[0.003]^{*}$

0.008 0.008

Two days after the event [0.003 $]^{*}$ $[0.003]^{*}$

Two days after the event

$$
0.003
$$

0.003

$$
\text { [0.005] }
$$$$
\text { [0.005] }
$$

Stock Market return

0.688
$0.067]^{* * *}$
0.006
$0.001]^{* * *}$

Observations

$$
472
$$$$
0.003
$$

R-squared 0.21

0.69
$[0.070]^{* * *}$
0.006
$[0.001]^{* * *}$

0.686

All regressions include day of the week fixed effects and firm-event fixed effects.

Robust standard errors clustered at the firm level in brackets.

* significant at $10 \%$; ** significant at $5 \%$; *** significant at $1 \%$ 